\title{
Dendrite regeneration of adult Drosophila sensory neurons diminishes with aging and is inhibited by epidermal-derived matrix metalloproteinase 2
}

\author{
Laura DeVault, Tun Li, Sarah Izabel, Katherine L. Thompson-Peer, Lily Yeh Jan, and Yuh Nung Jan \\ Howard Hughes Medical Institute, Department of Physiology, Department of Biochemistry and Biophysics, University \\ of California at San Francisco, San Francisco, California 94158, USA
}

\begin{abstract}
Dendrites possess distinct structural and functional properties that enable neurons to receive information from the environment as well as other neurons. Despite their key role in neuronal function, current understanding of the ability of neurons to regenerate dendrites is lacking. This study characterizes the structural and functional capacity for dendrite regeneration in vivo in adult animals and examines the effect of neuronal maturation on dendrite regeneration. We focused on the class IV dendritic arborization (c4da) neuron of the Drosophila sensory system, which has a dendritic arbor that undergoes dramatic remodeling during the first $3 \mathrm{~d}$ of adult life and then maintains a relatively stable morphology thereafter. Using a laser severing paradigm, we monitored regeneration after acute and spatially restricted injury. We found that the capacity for regeneration was present in adult neurons but diminished as the animal aged. Regenerated dendrites recovered receptive function. Furthermore, we found that the regenerated dendrites show preferential alignment with the extracellular matrix (ECM). Finally, inhibition of ECM degradation by inhibition of matrix metalloproteinase $2(\mathrm{Mmp} 2)$ to preserve the extracellular environment characteristics of young adults led to increased dendrite regeneration. These results demonstrate that dendrites retain regenerative potential throughout adulthood and that regenerative capacity decreases with aging.
\end{abstract}

[Keywords: adult; dendrite; regeneration; tissue; remodeling; aging]

Supplemental material is available for this article.

Received October 15, 2017; revised version accepted February 26, 2018.

Dendrite injury can result from acute injury to the neuron or progressive degeneration of the neuron. Alzheimer's disease, depression, and stroke are associated with loss of dendrite complexity, spine loss, and dendritic withering (Koleske 2013; Vickers et al. 2016). Indeed, the severity of dendrite loss may correlate with the severity of behavioral deficits (Falke et al. 2003). Whereas the importance of dendrite loss in these conditions is well recognized, dendrite recovery and regeneration remain unstudied. Recent studies reveal that dendrites can regenerate upon injury during development in Drosophila larvae (Song et al. 2012; Stone et al. 2014; Thompson-Peer et al. 2016), and dendrite regeneration also takes place in young adult Drosophila and Caenorhabditis elegans (Stone et al. 2014; Oren-Suissa et al. 2017). It will be important to examine the quality of the regenerated dendrite and determine whether dendritic regenerative capacity persists throughout adulthood. However, these inquires have been hampered by the difficulty of following the pro-

Corresponding author: yuhnung.jan@ucsf.edu Article published online ahead of print. Article and publication date are online at http://www.genesdev.org/cgi/doi/10.1101/gad.308270.117. gression of dendrite regeneration over time. To further our understanding of dendrite regeneration in adults, we established a system to study dendrite regeneration in the peripheral nervous system of adult Drosophila.

Drosophila dendritic arborization (da) neurons are well suited for studying the mechanisms of dendrite regeneration. Adjacent neurons nonredundantly cover the epithelium of the larval body wall and the adult abdomen. Their dendritic arbors are primarily restricted in a two-dimensional space by the surrounding epithelia (Grueber et al. 2002). The position and elaborate morphology of the dendritic arbor have facilitated many in vivo studies of dendrite development (Jan and Jan 2010; Dong et al. 2015). Interestingly, these neurons develop and elaborate a dendritic arbor twice: once during the larval stage and again during metamorphosis (Kuo et al. 2005, 2006; Williams and Truman 2005a,b). The dendritic arbor of the class IV

(C) 2018 DeVault et al. This article is distributed exclusively by Cold Spring Harbor Laboratory Press for the first six months after the full-issue publication date (see http://genesdev.cshlp.org/site/misc/terms.xhtml). After six months, it is available under a Creative Commons License (Attribution-NonCommercial 4.0 International), as described at http://creativecommons.org/licenses/by-nc/4.0/. 
da (c4da) neuron that degenerated during the early pupal stage is then re-elaborated subsequently during the pupal phase and extends into the space between the lateral abdominal muscles and the epithelium. Initially, the arbor extends radially from the center of the abdominal segment. Within the first $3 \mathrm{~d}$ after eclosion, the orientation of the dendritic arbor matures, taking a lattice-like orientation that aligns with the lateral muscles of the abdomen. This change in orientation depends on tissue remodeling after eclosion, which is specifically mediated by matrix metalloproteinase $2(\mathrm{Mmp} 2)$ secretion from the epidermal epithelial cells (Yasunaga et al. 2010). The arbor remains stable in orientation and dendrite length after this change for at least $21 \mathrm{~d}$ (Shimono et al. 2009), presenting the opportunity to study adult dendrites in vivo as the animal ages.

Previously, it was reported that the c4da neuron in newly eclosed Drosophila is capable of regenerating dendrites following injury (Stone et al. 2014). This raised several interesting questions: (1) Does the neuron's ability to regenerate dendrites change with aging? (2) What is the quality of the regenerated dendrites in terms of their morphology and function? (3) What regulates the capacity of dendrite regeneration? We were particularly interested in finding ways by which to enhance a neuron's ability to regenerate dendrites, which might lead to therapeutic applications. To examine injury and regeneration of dendrites, we chose to focus on v'ada, a c4da neuron with a favorable location, for our experiments in the adult Drosophila. We first developed a novel method to follow changes in individual identifiable neurons in vivo at multiple time points in adult flies. Without the ability to repeatedly image the same animal as the adult fly ages, previous studies of c4da neurons in Drosophila adults had relied on imaging the mounted abdomens of dissected animals in terminal experiments or were limited to the period immediately after eclosion (Shimono et al. 2009; Stone et al. 2014). While protocols have been developed to mount legless adults for time lapse imaging sessions of up to $12 \mathrm{~h}$ (Yasunaga et al. 2010), this approach was terminal. To study dendrite recovery from injury, we needed to enable animals to survive multiple imaging sessions and fully recover. Whereas it is possible to repeatedly image the wings of intact adults to study the regeneration of axons of wing neurons after injury (Soares et al. 2014; Brace and DiAntonio 2017), those wing neurons are unsuitable for examining dendrite architecture because they lack complex dendritic arbors.

Using the adult c4da neuron system, we characterized the recovery from injury and examined how tissue remodeling affects regenerative growth of the dendrites. Here, we show that adult neurons can regenerate dendritic arbors after injury. Regenerated dendrites have structural features that are less complex than those of uninjured neurons, as indicated by the total dendritic length, territory coverage, and the presence of stabilized microtubules. Nevertheless, the regenerated dendrites recovered their ability to respond to sensory stimuli. The regenerative capability of the dendrites declined with the age of the fly, starting at $3 \mathrm{~d}$ after eclosion. This decline corresponded with the period of dendritic remodeling. Preventing den- dritic remodeling through knockdown of $m m p 2$ preserved the extracellular matrix (ECM) and increased dendrite regeneration.

\section{Results}

\section{Adult dendrites can regenerate, but incompletely}

To examine the response of adult dendrites to injury, we established a novel method to repeatedly image the same identified neuron in anesthetized adult Drosophila. To achieve this, we developed a padded chamber for mounting adult flies exposed to a carbon dioxide source as an anesthetic, where the abdomen is positioned so that it is suitable for confocal imaging (Fig. 1A; Supplemental Fig. S1A). Flies were anesthetized only during the injury procedure and subsequent imaging sessions and were otherwise housed in individual vials.

Adult flies were initially anesthetized on ice. Once the flies were placed into the padded chamber, we severed the dendrites of individual neurons using a two-photon laser (Fig. 1B). Using the laser-mediated focal injury, all dendrites were severed at the first branch point, as described in previous studies of larval dendrite regeneration (Stone et al. 2014; Thompson-Peer et al. 2016).

Having established a technique that allowed us to image as well as injure the dendrites of c4da neurons in vivo in adult flies, we then tested whether dendrites had the ability to regenerate by following dendritic growth of the same neurons after injury in the same fly. We chose to perform our experiments on v'ada neurons because this subset of c4da neurons is situated at the ventral surface of the abdomen and not obscured by dark pigment, making it particularly well suited for our experimental protocol. Laser-mediated focal injury to v'ada was performed at $1 \mathrm{~d}$ after eclosion. Using imaging $1 \mathrm{~d}$ after severing all dendrites, we found that dendrites distal to the site of injury had degenerated. For all experiments, we imaged neurons at $1 \mathrm{~d}$ after injury to confirm that all dendrites had been fully severed and subsequently degenerated $(+1 \mathrm{~d})$ (Fig. 1C, top left). At $7 \mathrm{~d}$ after injury, neurons were again imaged to assess dendrite regrowth $(+7 \mathrm{~d})$ (Fig. 1C, top right). Although focal in nature, laser injury of the abdomen also injured surrounding tissues. We noted injury and subsequent degeneration of the lateral muscle of the abdomen, typically one or two muscle fibers (Supplemental Fig. S1B). The dendrite arbor of each neuron covers a defined territory of the body wall. We quantified regeneration as the total change in dendrite length in micrometers between +1 and $+7 \mathrm{~d}$ after injury and as the fraction of the total territory that is covered by regenerated dendrites at $+7 \mathrm{~d}$ after injury (Figs $1 \mathrm{C}, \mathrm{D}, 3 \mathrm{C}$, below). For all experiments, control uninjured neurons were also mounted during injury and imaged at all time points.

We found that, after injury at $1 \mathrm{~d}$ after eclosion, most neurons of the adult flies did regrow dendrites by $7 \mathrm{~d}$ after injury. Adjacent uninjured control neurons did not grow in length between +1 and $+7 \mathrm{~d}$ after injury. In contrast, neurons whose dendrites had been severed demonstrated significant increases in dendrite length and territory 

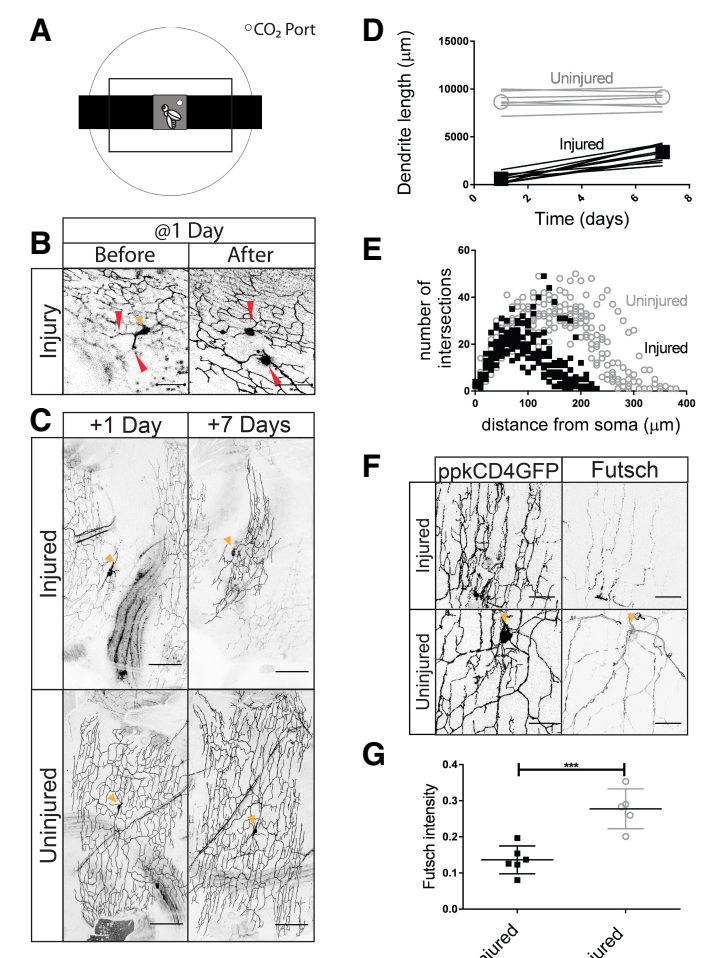

E
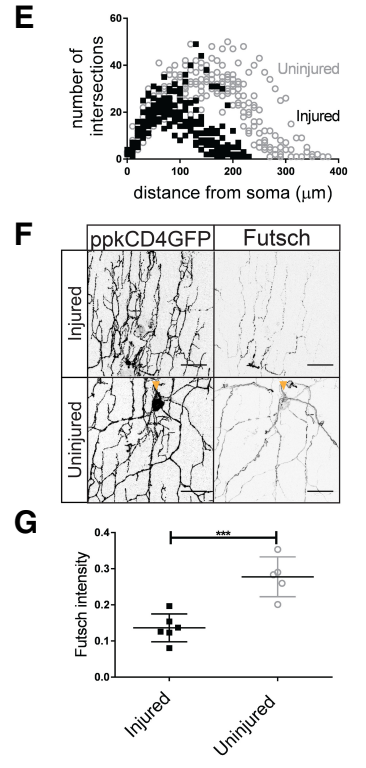

Figure 1. Dendrites regenerate $1 \mathrm{~d}$ after eclosion. $(A)$ Chamber to image anesthetized adult Drosophila. $(B)$ v'ada neurons in the adult abdomen are injured at the first branching points in the dendritic arbor $1 \mathrm{~d}$ after eclosion. Bar, $50 \mu \mathrm{m}$. Red arrowheads indicate the injury location. The orange arrowhead indicates the cell body of the neuron when visible in the plane of the image. (C, top panels) Neurons at 1 and $7 \mathrm{~d}$ after injury. (Bottom panels) Uninjured control neurons. Bar, $80 \mu \mathrm{m}$. $(D)$ Total dendrite length at 1 and $7 \mathrm{~d}$ after injury. Injured neurons $(M=2738$; SD $=880)$ had a greater change in dendrite length than uninjured neurons $(M=$ 255 ; $\mathrm{SD}=306) . t_{(15)}=7.11 . P<0.0001 . n=10$ injured; $n=7$ uninjured. For all graphs, open circles represent uninjured neurons, and solid squares represent injured neurons. $(E)$ Sholl analysis of injured and uninjured neurons at $7 \mathrm{~d}$ after injury. $(F)$ Injured and uninjured dendrites were stained for Futsch. $(G)$ The average intensity along the primary branch is plotted. Uninjured neurons had greater intensity $(M=0.28 ; \mathrm{SD}=0.055)$ than injured neurons $(M=0.14 ; \mathrm{SD}=0.038) . t_{(9)}=5.0 . P=0.0007 . n=6$ injured; $n=5$ uninjured. Bar, $20 \mu \mathrm{m}$.

coverage over this time (Fig. 1D). Although regenerated dendrites displayed significant regrowth, the regenerated arbors failed to occupy the same area or regrow to the same total dendrite length as uninjured neurons. Between $+1 \mathrm{~d}$ and $+7 \mathrm{~d}$ after injury, we observed an increase of 250 $\mu \mathrm{m} \pm 300 \mu \mathrm{m}$ in uninjured neurons compared with an increase of $2700 \mu \mathrm{m} \pm 900 \mu \mathrm{m}$ in injured neurons (Fig. 1D). The arbors of injured neurons were also more compact and smaller than those of uninjured neurons, occupying only $33 \% \pm 13 \%$ of the territory occupied by control uninjured neurons (Figs 1E, 3C, below). Neighboring neurons did not influence the extent of dendrite regeneration. Injured neurons with intact uninjured neighbors regenerated dendritic arbors with dendritic lengths and coverage areas statistically indistinguishable from injured neurons with injured or absent neighboring neurons (Supplemental Fig. S1C-E).

In addition to assessing the length and coverage of the regenerated dendrites, we wanted to examine the structural integrity of the dendrites. To assess the cytoskeletal structures of regenerated dendrites, we examined microtubule stability in the injured and uninjured arbors. Futsch, the Drosophila homolog of Map1B, is associated with stabilized microtubules and is found in the axons, cell bodies, and dendrites of neurons (Hummel et al. 2000). Previous studies have shown that Futsch is highly expressed in primary branches and at lower levels in secondary branches but is rarely detectable in tertiary branches (Ferreira et al. 2014; Sears and Broihier 2016). In uninjured neurons, we observed strong Futsch staining along primary branches and weaker staining of higher-order branches. In injured neurons, we observed patchy and weaker Futsch staining in the primary branches and throughout the regenerated dendritic arbor (Fig. 1F). We selected the most intensely stained Futsch branches for comparison with primary branches in injured and uninjured neurons and found that regenerated dendrites had significantly weaker Futsch intensity compared with uninjured neurons (Fig. 1G). This suggests that regenerated dendrites are different from uninjured dendrites.

\section{Injured dendrites recover functionality}

We next tested whether regenerated dendritic branches could also functionally recover. Larval c4da neurons are polymodal; they respond to light and thermal, chemical, and mechanical stimuli (Tracey et al. 2003; Hwang et al. 2007; Xiang et al. 2010; Boiko et al. 2012; Gorczyca et al. 2014; Guo et al. 2014; Mauthner et al. 2014). Delivery of an acid stimulus is sufficient to drive larval c4da neurons to the threshold and evoke a burst of action potentials (Boiko et al. 2012). To test the ability of regenerated neurons to functionally respond, we performed electrophysiology experiments using acidified solutions to stimulate injured neurons $7 \mathrm{~d}$ after injury as well as uninjured neurons in age-matched flies as a control. Neurons were injured at $1 \mathrm{~d}$ after eclosion. At $1 \mathrm{~d}$ after injury, balded neurons-namely, neurons whose dendrites have all been severed and subsequently degenerated after injury but have not yet regenerated-did not respond to an acid stimulus (Supplemental Fig. S2A). At $7 \mathrm{~d}$ after injury, injured and uninjured neurons were indistinguishable in their responses to acid stimulation. To better characterize the response to acidified stimulation, we performed a dose response curve using solutions with acidity ranging from $\mathrm{pH} 3$ to $\mathrm{pH}$ 7. Maximal response was observed at $\mathrm{pH} 3$, and the response declined at $\mathrm{pH} 4$. No substantial response was observed at $\mathrm{pH} 5$ or higher. Uninjured neurons had a firing rate of $14.9 \mathrm{~Hz} \pm 6.9 \mathrm{~Hz}$ and injured neurons had a firing rate of $10.1 \mathrm{~Hz} \pm 4.0 \mathrm{~Hz}$ at $\mathrm{pH} 3$ (Fig. 2A,B).

The response to mechanical stimuli depends on the presence of Ppk26 in larvae (Gorczyca et al. 2014; Guo et al. 2014; Mauthner et al. 2014). While no studies have yet demonstrated that adult neurons respond to 

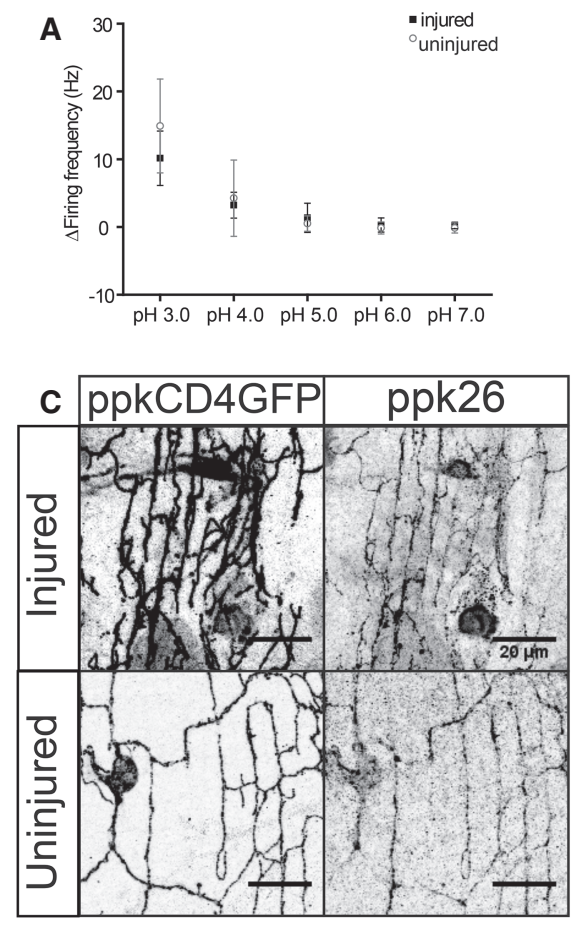

mechanical stimuli, adult c4da neurons express Ppk26 (Fig. 2C). Appropriate expression and trafficking of ion channels is a minimal requirement for neuronal function. The presence of neuron-specific ion channels suggests that neurons are competent to respond to stimuli. To test for the expected ion channel presence, we performed immunohistochemistry using a Ppk26 antibody. We found that Ppk26 was present in both injured and uninjured v'ada dendrites (Fig. 2C). This suggests that regenerated v'ada dendrites could be competent to respond to mechanical stimuli in addition to chemical stimuli. We also tested whether Ppk26 was required for the response to acid stimulation and found that Ppk26 is not required. We tested adult c4da neurons in ppk26 $6^{\Delta 11} / D f(3 L) E^{2 x e l} l^{8104}$ flies, which are null for ppk26, and observed bursting action potentials similar to those observed in wild-type flies (Supplemental Fig. S2B).

The capacity for dendrite regeneration diminishes with age

After observing that dendrites of v'ada neurons are capable of regrowth at $1 \mathrm{~d}$ after eclosion, we wanted to determine whether regeneration was possible in older adults. Dendrites undergo extensive remodeling and rearrangement 2 d after eclosion (Shimono et al. 2009; Yasunaga et al. 2010), so it was especially important to determine whether these neurons could regenerate dendrites after this reshaping was complete and they had achieved a stable morphology. To assess the potential and quality of regeneration as a function of age, we severed all dendrites in the neurons of adults that were either 3,7 , or $30 \mathrm{~d}$ old; confirmed injury $1 \mathrm{~d}$ later $(+1 \mathrm{~d})$; and assessed regeneration $7 \mathrm{~d}$ later $(+7 \mathrm{~d})$. Animals $>30 \mathrm{~d}$ old were too frail to survive the injury experiment and subsequent imaging.

We found that neurons in animals at all ages tested could regenerate after injury (Fig. 3A,B). However, the extent of regenerative capacity diminished in older animals. In terms of dendrite length, neurons injured at 3, 7, or $30 \mathrm{~d}$ regrew only half as much as neurons injured in 1-d-old adults. Neurons injured in 3-, 7-, and 30-d-old adults regrew $1400 \mu \mathrm{m} \pm 700 \mu \mathrm{m}, 1300 \mu \mathrm{m} \pm 600 \mu \mathrm{m}$, and 1400 $\mu \mathrm{m} \pm 500 \mu \mathrm{m}$ of dendritic length, respectively, over the 7-d period after injury, compared with neurons injured at $1 \mathrm{~d}$ that regrew $2700 \mu \mathrm{m} \pm 900 \mu \mathrm{m}$. Uninjured controls from 1, 3, 7, and $30 \mathrm{~d}$ grew $250 \mu \mathrm{m} \pm 300 \mu \mathrm{m}, 150 \mu \mathrm{m} \pm$ $350 \mu \mathrm{m},-400 \mu \mathrm{m} \pm 600 \mu \mathrm{m}$, and $200 \mu \mathrm{m} \pm 530 \mu \mathrm{m}$, respectively, between +1 and $+7 \mathrm{~d}$ after injury of adjacent neurons (Fig. 3B). In terms of the area of territory covered by regenerated dendrites, the areas covered by 1 -d-old and 3 -d-old adult neurons $(33 \% \pm 13 \%$ and $27 \% \pm 17 \%)$ were comparable (Fig. 3C). However, neurons injured in 7-dold adults recovered $17 \% \pm 12 \%$ (approximately half the territory of neurons injured in 1-d-old adults), while neurons injured in 30 -d-old adults could cover only $11 \% \pm$ $6 \%$ (approximately a third of the area of neurons injured in 1-d-old adults). Thus, we found that the ability to regrow dendrites in length declined between 1- and 3-d-old animals but then remained stable, whereas the ability to recover body wall territory with regenerated dendrites decreased gradually with age.

Dendrite structure was disorganized in all regenerated neurons at all time points. One measure for dendrite disorganization is the number of dendritic crossing events. These dendrites normally display self-avoidance, where the sister branches of the same neuron do not cross one another. To account for the reduced size of injured dendritic 

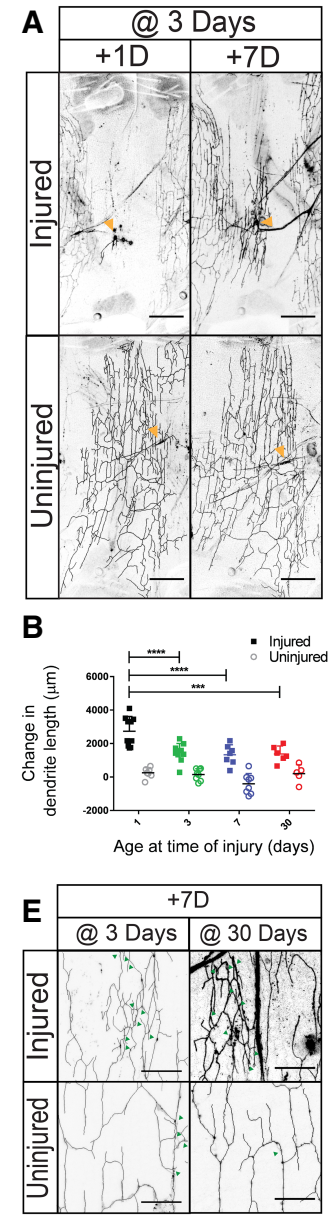

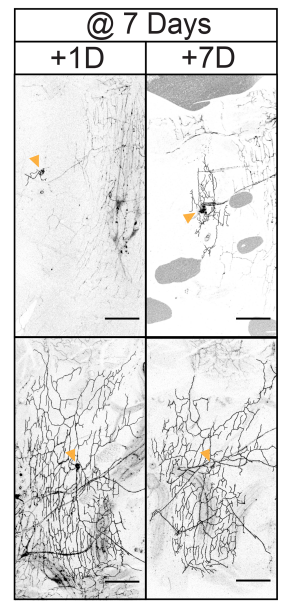

C
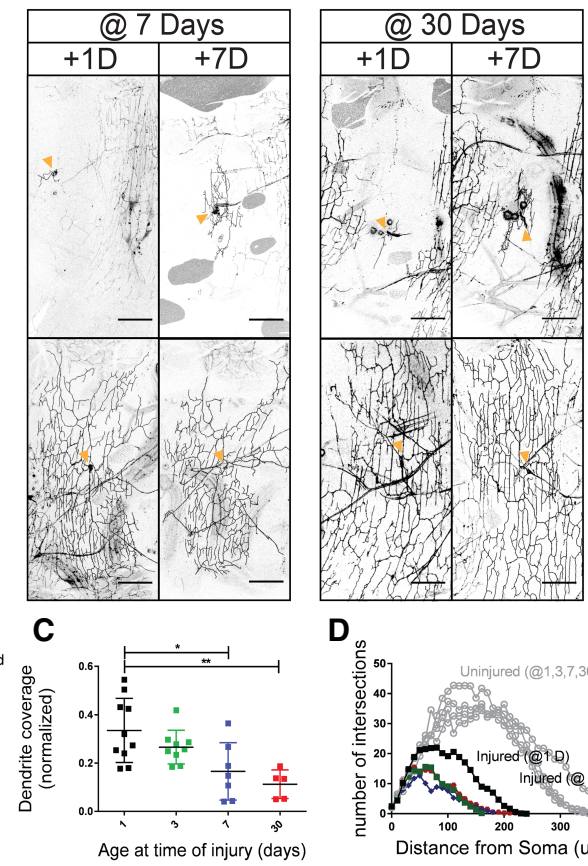

$\mathbf{D}_{0}$

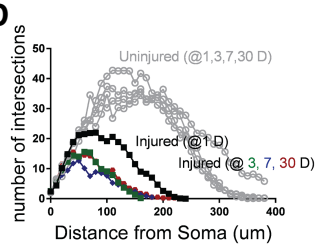

$\mathbf{F}$

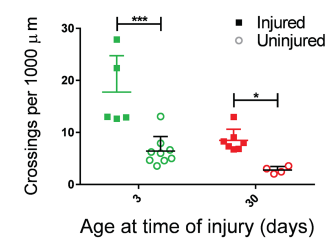

Figure 3. Dendrites regenerate at 3, 7, and $30 \mathrm{~d}$ after eclosion. (A) Neurons were injured at 3,7 , and $30 \mathrm{~d}$ after eclosion. The dendritic arbor is shown 1 and $7 \mathrm{~d}$ after injury. Orange arrowheads indicate the cell body of the neuron when visible in the plane of the image. Bar, 80 $\mu \mathrm{m} .(B)$ The difference in dendrite length between 1 and $7 \mathrm{~d}$ after injury for neurons injured at $1,3,7$, and $30 \mathrm{~d}$ after eclosion. Measured differences in dendrite length were subjected to a two-way ANOVA. Injury $\left[F_{(1,53)}=119.2\right.$, $P<0.0001]$ and age $\left[F_{(3,53)}=8.757, P<0.0001\right]$ were statistically significant. The interaction effect was significant if $F_{(3,53)}=3.880 . P=0.0140$. Sidak's post hoc test revealed that neurons injured at $1 \mathrm{~d}$ after eclosion $(M=2738$; $S D=$ $880)$ had greater dendrite length than neurons injured at 3 $\mathrm{d}(M=1393 ; \mathrm{SD}=710), 7 \mathrm{~d}(M=1333 ; \mathrm{SD}=598)$, and $30 \mathrm{~d}$ $(M=1375 ; \mathrm{SD}=479)$ after eclosion. $n=10$ injured and $n=$ 8 uninjured neurons $1 \mathrm{~d}$ after eclosion; $n=10$ injured and $n=8$ uninjured $3 \mathrm{~d}$ after eclosion; $n=7$ injured and $n=8$ uninjured $7 \mathrm{~d}$ after eclosion; $n=5$ injured and $n=5$ uninjured $30 \mathrm{~d}$ after eclosion. (C) Dendrite coverage of injured neurons measured $7 \mathrm{~d}$ after injury. Area coverage by dendrites was subjected to a one-way ANOVA. $F_{(3,27)}=6.575$. $P=0.0018$. Sidak's post hoc test revealed that neurons injured at $1 \mathrm{~d}$ after eclosion $(M=0.33$; $\mathrm{SD}=0.13)$ covered a greater area than neurons injured at $7 \mathrm{~d}(M=0.17$; $\mathrm{SD}=$ $0.12)$ and $30 \mathrm{~d}(M=0.11 ; \mathrm{SD}=0.06)$ after eclosion. $(D)$ Sholl analysis of regenerated neurons and uninjured controls for neurons injured at 1, 3, 7, and $30 \mathrm{~d}$ after eclosion. $(E)$ Injured and uninjured dendrites of neurons injured at 3 and $30 \mathrm{~d}$. Bar, $20 \mu \mathrm{m}$. Green arrowheads represent crossing events. $(F)$ Dendritic crossing events per $1000 \mu \mathrm{m}$. Dendritic crossing events were analyzed with a twoway ANOVA. Injury $\left[F_{(1,21)}=30.03 ; P<0.0001\right]$ and age $\left[F_{(1,21)}=17.34 ; P=0.0004\right]$ were significant. $n=5$ injured and $n=9$ uninjured neurons at $3 \mathrm{~d}$ after eclosion; $n=7$ injured and $n=4$ uninjured at $30 \mathrm{~d}$ after eclosion. arbors, crossing events were normalized to dendritic length. We examined crossing events in neurons injured at 3 and $30 \mathrm{~d}$ after eclosion (Fig. 3E). At both times points, injured neurons had a greater number of self-crossing defects than that of uninjured neurons (Fig. 3F).

\section{Epidermal-derived Mmp2 mediates ECM reorganization and inhibits regenerative capacity}

Adult c4da neurons undergo a dramatic transformation after eclosion. Neurons from animals that have just eclosed have a radial orientation that is then reorganized into a lateral or lattice-like orientation within $3 \mathrm{~d}$ after eclosion. This period corresponds with the decline in dendrite regenerative capacity. Our data above demonstrate that neurons can regrow dendrites after injury before and after this transition. We hypothesized that neuronal remodeling might influence the extent of dendrite outgrowth after injury. Remodeling depends on epidermal secretion of Mmp2 (Yasunaga et al. 2010). To address the role of neuronal remodeling in dendrite regeneration, we examined regeneration in $m m p 2$ mutants. We measured the regenerative ability of dendrites in Drosophila transheterozygous for an allele of $m m p 2^{M I O 0489}$ and a deficiency for $m m p 2, D f(2 R) B S C 132$. After confirming dendrite degen- eration $+1 \mathrm{~d}$ after injury, we measured dendrite regrowth and coverage at $+7 \mathrm{~d}$ after injury (Fig. $4 \mathrm{~A}-\mathrm{C}$ ). We found that compared with injured wild-type neurons, injured neuron regrowth and coverage was greater in $\mathrm{mmp} 2 \mathrm{mu}-$ tants. While wild-type neurons regrew $2700 \mu \mathrm{m} \pm 800$ $\mu \mathrm{m}$ of dendrite length and recover $31 \% \pm 3 \%$ of their territory, $\mathrm{mmp} 2$ mutants regrew $4200 \mu \mathrm{m} \pm 800 \mu \mathrm{m}$ and recovered $47 \% \pm 9 \%$ of their territory-an increase of $\sim 50 \%$ over wild-type (Fig. 4B,C). Total dendrite length of uninjured neurons was also greater in $\mathrm{mmp} 2$ mutants than in wild-type (Supplemental Fig. S3B). This suggests that $m m p 2$ inhibits dendrite outgrowth as well as dendrite regeneration after injury.

In the adult abdomen, the expression of $m m p 2$ is restricted to transient expression in the epidermal epithelial cells during a period directly after eclosion (Yasunaga et al. 2010). In addition to the role for MMPs in tissue remodeling, MMPs have been shown to facilitate wound healing and axon guidance in Drosophila (Miller et al. 2007; Huang et al. 2011; Stevens and Page-McCaw 2012). To determine from which cells mmp2 inhibits dendrite regeneration, we examined the effect of tissue-specific expression of mmp2 RNAi in the epidermal cells and c4da neurons. Epidermal expression of GMR51F10 (epidermal) Gal4 was confirmed using UAS-Red Stinger 

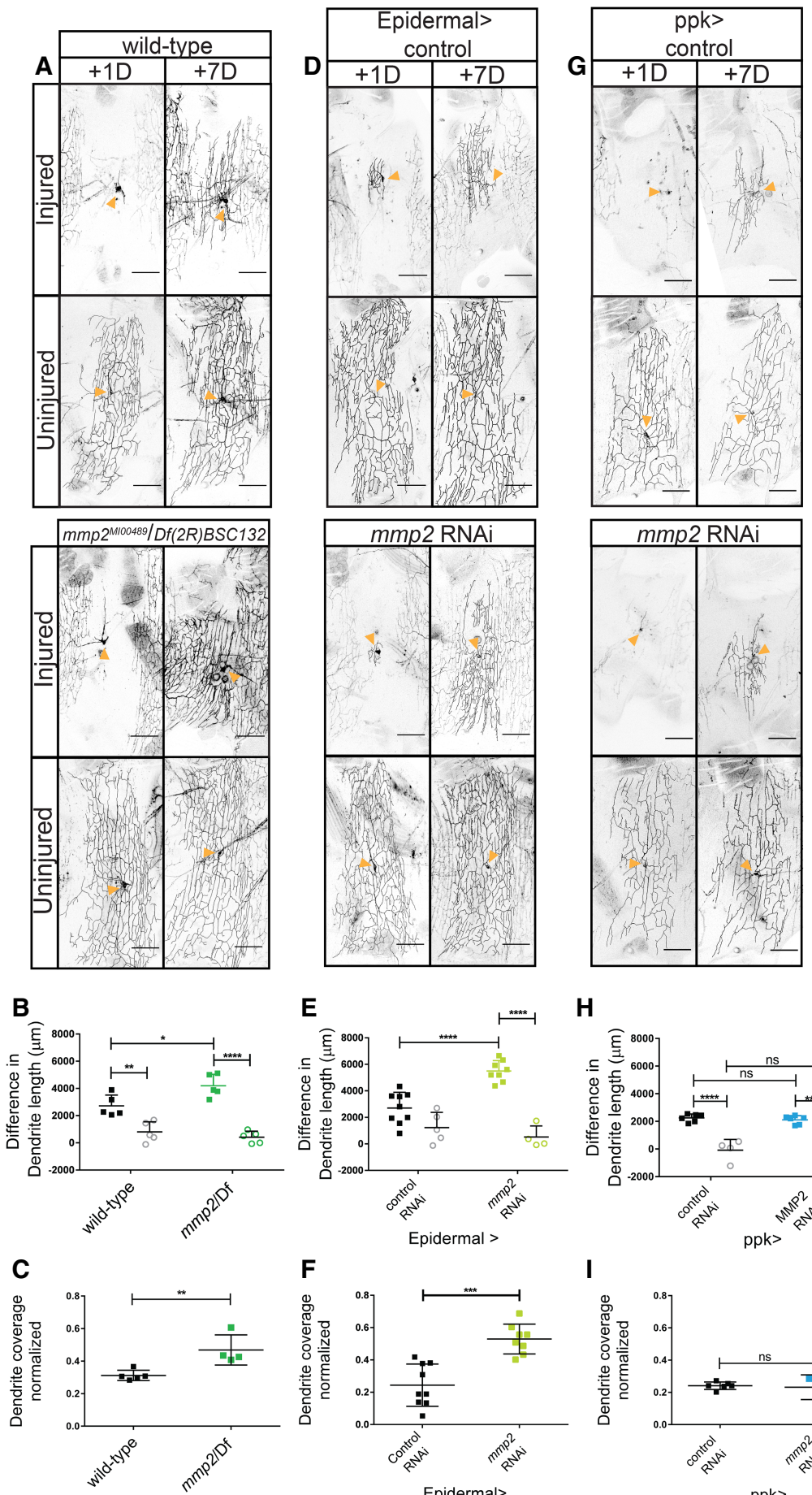

Epidermal>

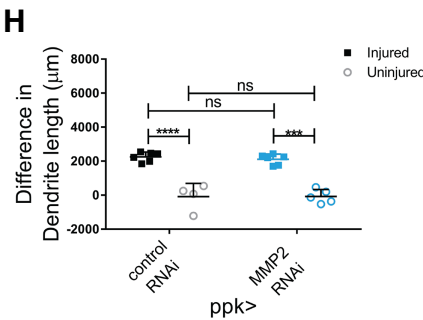

I

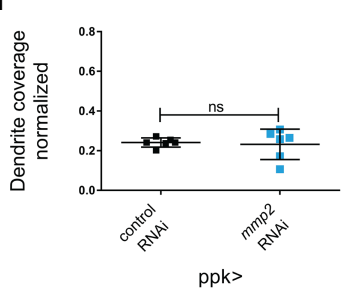

Figure 4. Loss of $m m p 2$ increases dendrite regeneration. (A) Wild-type and $m m p 2^{\text {MI00489 }} / D f(2 R) B S C 132$ neurons 1 and $7 \mathrm{~d}$ after injury. Orange arrowheads indicate the cell body of the neuron. $(B)$ Change in dendritic length $7 \mathrm{~d}$ after injury. Dendrite lengths were subjected to a twoway ANOVA. Injury increased the difference in dendrite length. $F_{(1,16)}=78.65 ; P<$ 0.0001 . Genotype was not statistically significant. $F_{(1,16)}=2.8394 . P=0.11$. The interaction effect was significant. $F_{(1,16)}=8.394$. $P=0.0105$. Tukey's post hoc test revealed that mmp2 injured neurons $(M=4199$; $\mathrm{SD}=835)$ grew more than wild-type injured neurons $(M=2722$; $\mathrm{SD}=790)$. Uninjured $m m p 2$ neurons $(M=412 ; \mathrm{SD}=439)$ were not different from wild-type uninjured neurons $(M=800 ; \mathrm{SD}=746) . n=5$ injured and $n=5$ uninjured wild type; $n=5$ injured and $n=5$ uninjured mmp2 mutants. $(C)$ Coverage of dendritic area at $7 \mathrm{~d}$ after injury. There was a significant difference between wild type $(M=0.3126 ; \mathrm{SD}=0.31)$ and $m m p 2(M=0.4693 ; \mathrm{SD}=0.093) . t_{(7)}=$ 3.580; $P=0.0090 .(D)$ Epidermal Gal4 drives expression of control (UAS-dcr2) and mmp2 (V107888) RNAi at 1 and $7 \mathrm{~d}$ after injury. (E) Change in dendritic length $7 \mathrm{~d}$ after injury. Changes in dendrite length were subjected to a two-way ANOVA. Injury $\left[F_{(1,22)}=58.05 ; \quad P<0.0001\right]$ and $\mathrm{mmp} 2$ RNAi $\left[F_{(1,22)}=6.035 ; P=0.0224\right]$ were significant. The interaction effect was significant. $F_{(1,22)}=17.14 . P=0.0004$. Sidak's post hoc test revealed that $m m p 2$ RNAi $(M=$ 5495; $\mathrm{SD}=787$ ) increased dendrite length compared with control RNAi $(M=2703$; $\mathrm{SD}=1188$ ) injured neurons. There was no difference between uninjured neurons in control RNAi $(M=1230 ; \mathrm{SD}=1147)$ and mmp2 RNAi $(M=518 ; \mathrm{SD}=837)$ neurons. $n=9$ injured and $n=5$ uninjured control RNAi neurons; $n=8$ injured and $n=4$ uninjured mmp2 RNAi neurons. $(F)$ Dendritic area $7 \mathrm{~d}$ after injury. There was a significant difference between control $(M=0.2436$; $\mathrm{SD}=0.13)$ and $m m p 2(M=0.5295 ; \mathrm{SD}=$ 0.092) RNAi. $t_{(15)}=5.137 . P=0.0001 .(G)$ Neuronal Gal4 (Ppk Gal4) drives expression of control (UAS-dcr2) and mmp2 (V107888) RNAi. $(H)$ Change in dendrite length $7 \mathrm{~d}$ after injury. Changes in dendrite length were subjected to a two-way ANOVA with two injured conditions (injured and uninjured)

and two RNAi conditions (control and $m m p 2$ ). There was a significant effect of injury. $F_{(1,13)}=92.12 . P<0.0001$. There was not a significant effect of RNAi $\left[F_{(1,13)}=0.1814 ; P=0.67\right]$ or an interaction effect $\left[F_{(1,13)}=0.56 ; P=0.47\right] . n=6$ injured and $n=4$ uninjured control RNAi neurons; $n=6$ injured and $n=5$ uninjured $m m p 2$ RNAi neurons. (I) Regenerated dendrite area $7 \mathrm{~d}$ after injury. There was not a significant difference between $m m p 2$ RNAi and control neurons. $t_{(8)}=0.9867 . P=0.3527$.

(Supplemental Fig. S2C). Expression of mmp2 RNAi in either the epidermis (Fig. 4D) or c4da neurons (Fig. 4G) did not affect total dendrite length of uninjured neurons (Supplemental Fig. S3C,D). We found that dendrite regenera- tion was enhanced by expressing mmp2 RNAi in the epidermis (Fig. 4E,F) but not in the c4da neurons (Fig. $4 \mathrm{H}, \mathrm{I}$ ). Knockdown of $m m p 2$ in epidermal cells increased dendrite growth and coverage in injured neurons 
(Fig. 4E,F). Epidermal knockdown of $m m p 2$ doubled the increase in dendrite length from $2700 \mu \mathrm{m} \pm 1200 \mu \mathrm{m}$ to $5500 \mu \mathrm{m} \pm 800 \mu \mathrm{m}$ and increased the area covered from $24 \% \pm 13 \%$ to $53 \% \pm 9 \%$ for injured neurons compared with controls. This suggests that mmp2 derived from the epidermal cells limits dendrite regeneration in adults.

\section{Dendrites preferentially regenerate into ECM-rich areas}

Neuronal maturation and the transition from radial to lattice-like dendrites are associated with local degradation of the ECM surrounding the dendrites in the area between the epidermal and muscle cells of the abdomen. Young neurons grow into an environment enriched with basement membrane (BM), as marked by collagen IV, known in Drosophila as viking (vkg). After Mmp2 expression in the epidermis during the $3 \mathrm{~d}$ after eclosion, the abdominal $\mathrm{BM}$ is degraded, and there are stripes of collagen IV between lateral muscles in the abdomen, but the BM no longer completely surrounds the muscles (Yasunaga et al. 2010). Visualizing collagen IV through a vkgGFP tag, we confirmed that expressing mmp2 RNAi in the epidermis inhibited collagen IV degradation to an extent at $3 \mathrm{~d}$ after eclosion (vkgGFP) (Fig. 5A,B).

To explore the importance of ECM remodeling in the 3 $\mathrm{d}$ after eclosion and dendrite regeneration, we performed a series of dendrite injury experiments using a temperature- sensitive allele of $m m p 2$, Y53N (Page-McCaw et al. 2003; Wang and Page-McCaw 2014). Transheterozygous flies for $m m p 2^{Y 53 N}$ and $D f(2 R) B S C 132$ were lethal when raised at the nonpermissive temperature of $29^{\circ} \mathrm{C}$ and viable at the permissive temperature of $25^{\circ} \mathrm{C}$. Flies were viable when moved to the nonpermissive temperature after eclosion. Raised at the permissive temperature, wild-type and $m m p 2^{Y 53 N} / D f(2 R) B S C 132$ flies were either kept at $25^{\circ} \mathrm{C}$ or $29^{\circ} \mathrm{C}$ or shifted from $25^{\circ} \mathrm{C}$ to $29^{\circ} \mathrm{C} 3 \mathrm{~d}$ after eclosion. All injuries occurred at $3 \mathrm{~d}$ after eclosion, at which time all remodeling should be complete (Fig. 6A-C). When moved to the nonpermissive temperature at eclosion, we found that dendrites of $m m p 2^{Y 53 N} / D f(2 R) B S C 132$ neurons regrew to a greater extent than wild-type neurons, reaching a length of $2574 \mu \mathrm{m} \pm 612 \mu \mathrm{m}$ and $1523 \mu \mathrm{m} \pm$ $312 \mu \mathrm{m}$ and covering $30 \% \pm 9 \%$ and $22 \% \pm 5 \%$ of their territory (Fig. 6D,E). We observed no difference in total dendrite length in uninjured $m m p 2^{Y 53 N} / D f(2 R) B S C 132$ neurons and wild-type neurons raised at $29^{\circ} \mathrm{C}$ (Supplemental Fig. S3E). At the permissive temperature, $m m p 2^{Y 53 N} / D f(2 R) B S C 132$ neurons and wild-type neurons regrew to comparable lengths $(1834 \mu \mathrm{m} \pm 802 \mu \mathrm{m}$ and $1744 \mu \mathrm{m} \pm 593 \mu \mathrm{m}$, respectively) and areas $(23 \% \pm$ $11 \%$ and $21 \% \pm 8 \%$, respectively). No difference in regrowth was noted between neurons in flies shifted from the permissive to the nonpermissive temperature; $m m p 2^{Y 53 N} / D f(2 R) B S C 132$ neurons regrew to $1928 \mu \mathrm{m} \pm$
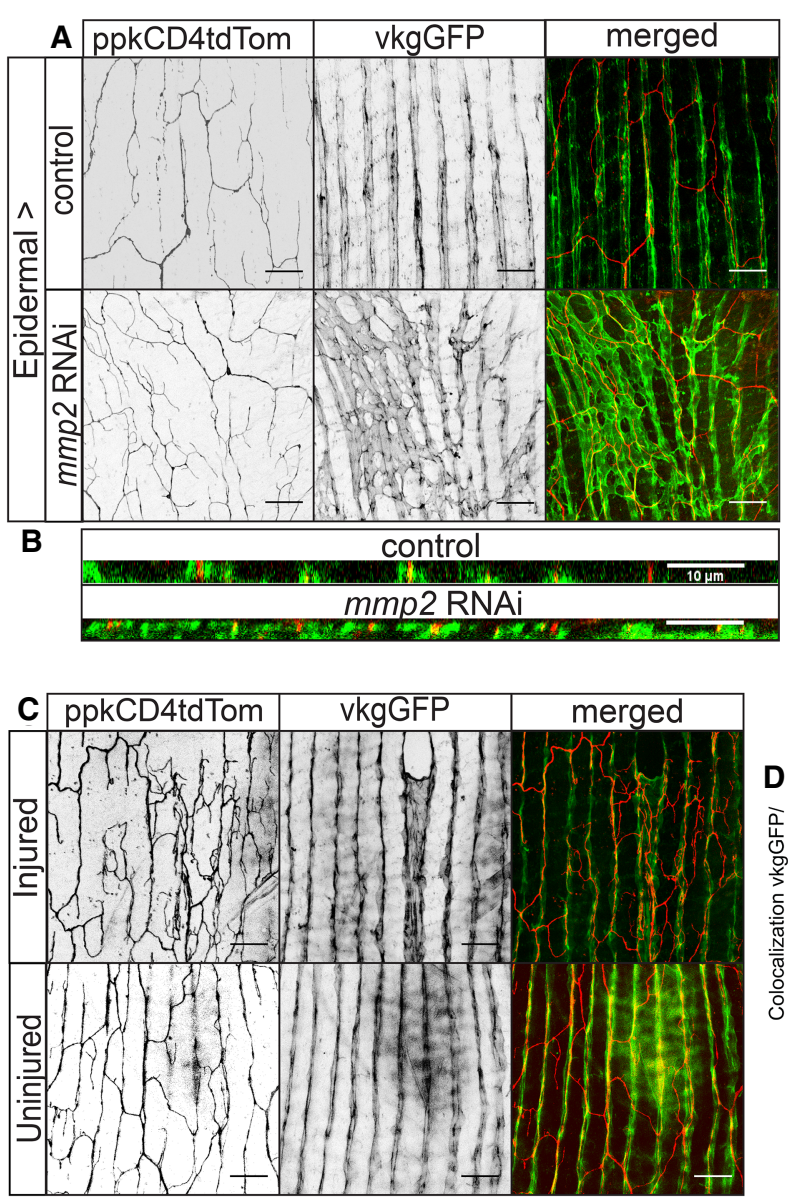

Figure 5. Regenerated dendrites associate with the ECM. (A) Epidermal expression of mmp2 RNAi partially preserves the ECM at $3 \mathrm{~d}$ after eclosion. Collagen IV (vkgGFP) marks the ECM. (B) XZ view of ECM and dendrite colocalization. $(C)$ Colocalization of neurons (ppkCD4tdTom) and collagen IV (vkgGFP) in injured and uninjured neurons at $7 \mathrm{~d}$ after injury. $(D)$ Proportion of the dendritic arbor that colocalizes with collagen IV. There was a significant difference between injured $(M=0.7762, \mathrm{SD}=0.12)$ and uninjured $(M=0.5828, \mathrm{SD}=0.031)$ neurons. $t_{(10)}$ =3.940; $P=0.0028 . n=6$ injured neurons; $n=$ 6 uninjured neurons.

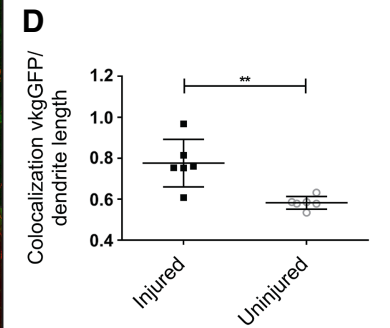



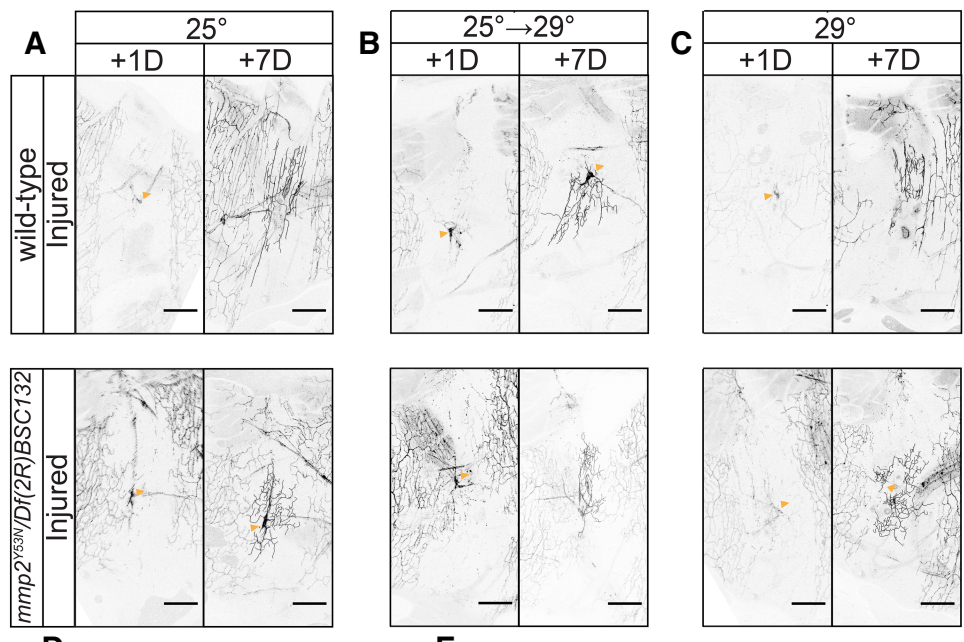

E
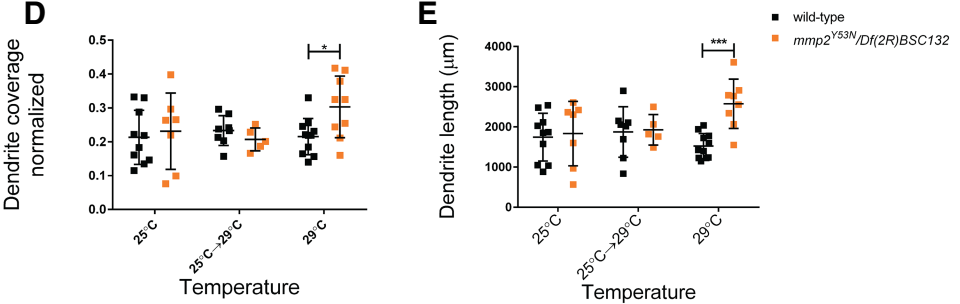

Figure 6. During the 3-d period after eclosion, $m m p 2$ influences dendrite regeneration. Wild-type and $m m p 2^{Y 53 N} / D f(2 R) B S C 132$ neurons were injured at $3 \mathrm{~d}$ after eclosion. Neurons were imaged at 1 and $7 \mathrm{~d}$ after injury. (A) Flies were kept at $25^{\circ} \mathrm{C}$. (B) Flies were raised at $25^{\circ} \mathrm{C}$ and shifted to $29^{\circ} \mathrm{C}$ at $3 \mathrm{~d}$ after eclosion. $(\mathrm{C})$ Flies eclosed at $25^{\circ} \mathrm{C}$ and were shifted to $29^{\circ} \mathrm{C}$ within $1 \mathrm{~d}$ of eclosion. $(D)$ The regenerated dendrite area after $7 \mathrm{~d}$ is plotted. Area coverage was subjected to a two-way ANOVA. There was not a significant effect of temperature. $F_{(2,44)}=1.513 . P=0.2314$. Genotype: $F_{(1,44)}=1.464$; interaction: $F_{(2,44)}=2.364 . P=0.1058$. Sidak's post hoc test revealed that at $29^{\circ} \mathrm{C}$, there was a difference between $m m p 2^{Y 53 N /} D f(2 R) B S C 132$ and wild-type neurons. $(E)$ Dendrite length $7 \mathrm{~d}$ after injury. Dendrite length was subjected to a two-way ANOVA. The effect of temperature was not significant. $F_{(2,43)}=0.9129 . P=0.4090$. Genotype $\left[F_{(1,43)}=5.612 ; P=0.0224\right]$ and interaction $\left[F_{(2,43)}=4.139\right.$, $P=0.0227]$ were significant. Sidak's post hoc test revealed that at $29^{\circ} \mathrm{C}, \mathrm{mmp} 2^{\mathrm{Y} 53 \mathrm{~N}} / \mathrm{Df}(2 \mathrm{R}) \mathrm{BSC} 132$ regenerated neurons $(M=2574, \mathrm{SD}=612)$ had greater dendrite length than wild-type neurons $(M=1523, \mathrm{SD}=312) . n=$ 10 wild-type and $n=7 \mathrm{mmp} 2^{Y 53 N} / D f(2 R) B S C 132$ neurons at $25^{\circ} \mathrm{C} ; n=8$ wild-type and $n=5 \mathrm{mmp} 2^{\mathrm{Y} 53 \mathrm{~N}} / \mathrm{Df}$ (2R)BSC132 neurons shifted from $25^{\circ} \mathrm{C}$ to $29^{\circ} \mathrm{C} ; n=11$ wild-type and $n=8 \mathrm{mmp} 2^{Y 53 N} / D f(2 R) B S C 132$ neurons at $29^{\circ} \mathrm{C}$.
$381 \mu \mathrm{m}$ and covered $21 \% \pm 3 \%$ of their territory, and wildtype neurons regrew to $1874 \mu \mathrm{m} \pm 628 \mu \mathrm{m}$ and covered $23 \% \pm 4 \%$ of their territory (Fig. 6D,E). This suggests that the primary influence of $m m p 2$ in dendrite regeneration occurs during the $3 \mathrm{~d}$ after eclosion.

To further examine the importance of the ECM in regeneration, we wanted to determine whether the presence of the ECM was favorable for growth of regenerating dendrites. To limit our study to neurons that had already undergone dendrite realignment, we injured neurons at $3 \mathrm{~d}$ after eclosion and looked at colocalization of collagen IV and dendrites $7 \mathrm{~d}$ after injury (Fig. 5C). In uninjured neurons, $58 \% \pm 3 \%$ of the dendritic arbor colocalized with collagen IV by $10 \mathrm{~d}$ after eclosion. After injury at $3 \mathrm{~d}$ after eclosion, $\sim 78 \% \pm 12 \%$ of regenerated dendrites colocalized with collagen IV-more than what was observed for uninjured dendrites (Fig. 5D). Thus, after injury, dendrites grow in ECM-rich regions. This may be due to either preferential growth on the ECM or selective elimination from non-ECM-rich areas. We note that the ECM may be altered in injured abdomens, particularly in areas corresponding to muscle or epidermal damage incurred during the dendrite injury procedure (Supplemental Fig. S1B; Fig. 5C).

\section{Integrin-mediated adhesion to the ECM regulates dendrite regeneration}

Given these observations of dendrite colocalization with collagen IV in adult flies and previous observations about dendrite disorganization of injured larval neurons (Thompson-Peer et al. 2016), we hypothesized that adhesion to the ECM could affect regenerative potential and in- fluence the increased crossing behavior of regenerated dendrites (Fig. 3E,F). Adherence to the ECM is influenced by neuronal expression of integrin, a heterodimeric cell surface receptor consisting of an $\alpha$ subunit and a $\beta$ subunit. Neuron-specific overexpression of myospheroid (mys; a $\beta$ integrin subunit), and multiple edematous (mew; an $\alpha$ integrin subunit) increases dendrite adhesion to the ECM. Uninjured dendrites of c4da neurons generally avoid dendrites of the same neuron. Without proper ECM attachment, dendrites fail to properly avoid each other. Forcing adhesion to the ECM influences the crossing behavior of dendrites. Integrin overexpression reduces the length of dendrites detaching from the ECM, thereby reducing the number of noncontacting self-crossing events, defined as events where dendrites cross over sister branches of the same neuron without direct contact. Upon integrin overexpression, dendrites are forced into the same plane as other dendrites and can no longer avoid each other by growing into a different plane (Han et al. 2012; Kim et al. 2012; Meltzer et al. 2016). In regenerated larval dendrites, increased adhesion to the ECM through overexpression of mys and mew increased the number of contacting crossings, defined as events where dendrites directly touched the dendrites they are crossing over (Thompson-Peer et al. 2016). Similarly, in adults, we found that overexpression of the integrin subunits mys and mew caused the contacting crossings of regenerated dendrites to increase from $8.7 \pm 1.8$ to $14 \pm 3$ per 1000 $\mu \mathrm{m}$. In contrast, expression of mew or mys RNAi in neurons decreased contacting crossings in regenerating dendrites to $4.1 \pm 1.9$ and $5.7 \pm 2.3$ per $1000 \mu \mathrm{m}$, respectively (Fig. 7A,B). Overexpressing integrin did not promote dendrite outgrowth. There was no difference in the growth of 


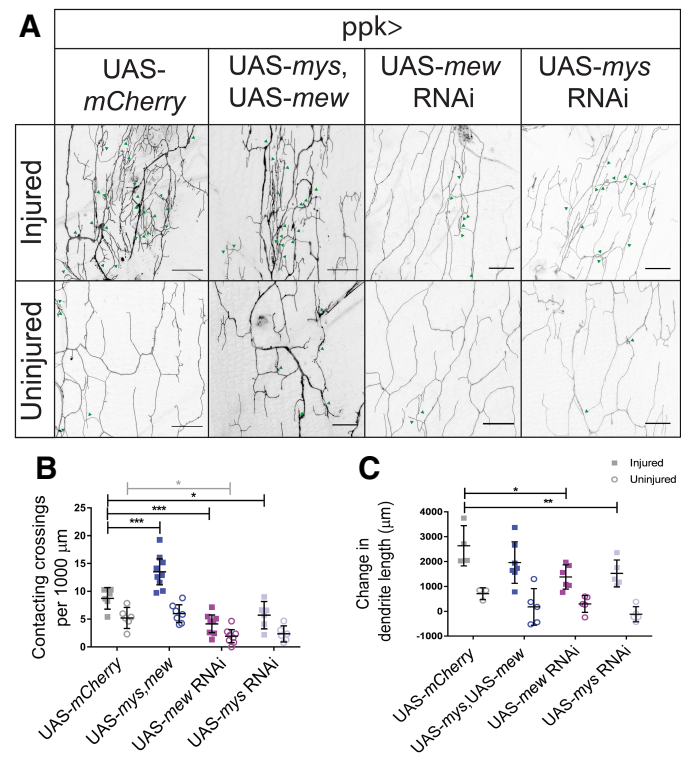

Figure 7. Integrin expression alters dendritic crossings and dendrite outgrowth of regenerated dendrites. $(A)$ Dendritic crossings of injured and uninjured neurons in neurons overexpressing integrin subunits mys and mew and expressing mew RNAi, mys RNAi, and mCherry. Bar, $20 \mu \mathrm{m}$. Green arrowheads indicate contacting crossings. $(B)$ Contacting crossing events were analyzed by a two-way ANOVA. Injury $\left[F_{(1,48)}=56.16 ; P<0.0001\right]$, integrin $\left[F_{(3,48,38)}=33.32 ; P<0.0001\right]$, and interaction $\left[F_{(3,48)}=4.945, P=\right.$ $0.0045]$ were significant. Post hoc analysis using Dunnett's test for multiple comparisons demonstrated that overexpression of mys, mew increased contacting crossings in injured neurons $(M=$ 13.5; $\mathrm{SD}=3.0)$ compared with overexpression of mCherry $(M=$ 8.7; $\mathrm{SD}=1.8)$. Knockdown of $\mathrm{mew}(M=4.1 ; \mathrm{SD}=1.9)$ and mys $(M=5.7 ; \mathrm{SD}=2.3)$ decreased contacting crossings compared with $m$ Cherry. Knockdown of mew $(M=1.9 ; \mathrm{SD}=1.4)$ decreased contacting crossings compared with $m$ Cherry expression $(M=5.2$; $\mathrm{SD}=1.8$ ) in uninjured neurons. $n=9$ injured and $n=7$ uninjured mys, mew; $n=6$ injured and $n=6$ uninjured $m$ Cherry; $n=8$ injured and $n=8$ uninjured mew RNAi neurons; $n=6$ injured and $n=6$ uninjured mys RNAi neurons. (C) Change in dendrite length upon integrin manipulation. Change in dendritic length was analyzed by two-way ANOVA. Injury $\left[F_{(1,32)}=67.48, P<0.0001\right]$ and integrin $\left[F_{(3,32)}=3.95, P=0.0166\right]$ were significant. There was no interaction effect. $F_{(3,32)}=0.9318 . P=0.4366$. Post hoc analysis using Sidak's multiple comparison test revealed that injured mys RNAi $(M=1526 ; \mathrm{SD}=539)$ and mew RNAi $(M=1380, \mathrm{SD}=487)$ had decreased changes in dendrite length compared with injured neurons expressing $m$ Cherry $(M=2636, \mathrm{SD}=808)$.

either control uninjured neurons or injured neurons overexpressing mys and mew as compared with neurons expressing mCherry. RNAi knockdown of mew or mys decreased dendritic growth after injury and decreased the total dendritic length of uninjured neurons (Fig. 7C; Supplemental Fig. S3A). These results demonstrate that in regenerating a dendritic arbor after injury, integrins have somewhat opposing roles in terms of dendritic length and organization. Loss of the integrin subunit mys or mew decreases the dendritic length of the arbor but increases the organization of the arbor, as measured through contacting crossing events.

\section{Discussion \\ Mature neurons regenerate dendrites}

Here, we characterize dendrite regeneration in adult animals. Regeneration of dendrites in adult animals has been shown previously for the PVD neuron of C. elegans (Kravtsov et al. 2017; Oren-Suissa et al. 2017) and immediately after eclosion in adult Drosophila (Stone et al. 2014). Our study is a significant advance in the study of dendrite regeneration in adult Drosophila because previous studies examined only the youngest possible adult Drosophila injured at the time of eclosion due to the fact that adults mounted at any time after eclosion did not survive (Stone et al. 2014). For the first few days after eclosion, these neurons display a highly dynamic dendrite morphology (Shimono et al. 2009; Yasunaga et al. 2010) and then achieve a stable dendrite shape. We confirm that neurons in young adult flies can regenerate their dendrites. We further characterize the regenerated dendrites. Regenerated dendrites have altered structure compared with uninjured dendrites, as indicated through reduced Futsch staining in primary branches. This could indicate that regenerated dendrites are more comparable with higher-order dendritic branches or fail to build structurally sound primary branches. We also establish that dendrite regeneration can occur in flies up to $30 \mathrm{~d}$ after eclosion and possibly even older in age. The persistence of regenerative capacity is reminiscent of studies of axon regeneration in adult Drosophila, in which sprouting after injury to the wing margin is observed at $14 \mathrm{~d}$. Older neurons regenerate axons at a slower rate than young neurons (Soares et al. 2014). These results suggest that neurons retain the ability to sprout dendrites and axons late in adult life, although at a diminished capacity compared with neurons in young animals.

\section{Comparison with juvenile dendrite regeneration}

Parallel studies in Drosophila larvae offer a point of comparison between regeneration during development and adulthood. The most apparent difference between neurons injured in adulthood and neurons injured during the larval period is the extent of regeneration, which is greater in larvae. In larval neurons injured at $48 \mathrm{~h}$ after egg laying, dendrites recover almost $80 \%$ of dendrite length and $\sim 50 \%$ of the area that is normally covered by an uninjured neuron within $3 \mathrm{~d}$ after injury (Thompson-Peer et al. 2016). Adult dendrites regrow to a much lesser extent. Even neurons injured at $1 \mathrm{~d}$ after eclosion recover by $7 \mathrm{~d}$ after injury only one-third of the dendrite length and the area normally covered by an uninjured neuron. Despite these differences, many of the features of regenerated dendrites are shared between the adult and larval neurons.

Striking features of regenerated dendrites are the disorganization and loss of regular structure. Both larval Drosophila da neurons and PVD neurons of C. elegans display a loss of self-avoidance in regenerated dendrites (Thompson-Peer et al. 2016; Oren-Suissa et al. 2017). We found that adult Drosophila c4da neurons also display selfavoidance defects of their regenerated dendrites when injured at 3 or $30 \mathrm{~d}$ after eclosion. 
We also demonstrated the functionality of regenerated dendrites in adults. In larvae, regenerated c4da neurons appropriately traffic Ppk26, a channel essential to neuronal function, and the regenerated class III da neurons show partial response to gentle touch after injury (Thompson-Peer et al. 2016). We demonstrated that regenerated adult neurons retain functional properties; they exhibit not only appropriate trafficking of Ppk26 but also electrophysiological responses to acid stimuli. This is the first demonstration of functional regeneration of adult dendrites.

\section{Tissue maturation impedes dendrite regeneration}

Our results suggest that degradation of the ECM creates a less permissive environment for dendrite outgrowth and regeneration. In Drosophila larvae, dendrite outgrowth is regulated in two phases. The initial stage of outgrowth, in which the dendrites must extend to cover the body wall, occurs when the ECM has low attachment to the epithelium. Increased ECM attachment to the epithelium, regulated by the epidermally derived microRNA bantam, decreases the plasticity and elaboration of dendrite growth (Parrish et al. 2009; Jiang et al. 2014). ECM regulation in adulthood also appears to have two phases. Young adults, during the phase in which the dendrites re-elaborate to cover the body wall, have an ECM-rich environment, permissive to dendrite outgrowth (Satoh et al. 2012). The ECM degrades within $3 \mathrm{~d}$ of eclosion (Yasunaga et al. 2010). We found that there was a pronounced difference between dendrite regeneration during the early period with a rich ECM and the period after ECM remodeling, suggesting that the completion of tissue remodeling may decrease dendrite regeneration. Thus, in both larvae and adults, the status of the ECM influences the ability of dendrites to grow and regenerate.

In support of the dependence of dendrite regeneration on the ECM, we found that $m m p 2$ mutants have increased dendrite regeneration. MMPs have a broad role in injury response, including breaking down the blood-brain barrier, glial scar formation, breakdown of inhibitory molecules, and proteolytic activation of trophic cues (PageMcCaw et al. 2007; Andries et al. 2017). Our results suggest that increased dendrite regeneration stems from the role for Mmp2 in remodeling the ECM. Mmp2 has been distinctly associated with BM remodeling during fat body remodeling and abdominal maturation (Llano et al. 2002; Yasunaga et al. 2010; Jia et al. 2014). Increased dendrite regeneration was specific to epidermal knockdown of $m m p 2$ and associated with partial preservation of the BM between muscle and the epidermis. This suggests that inhibiting tissue remodeling can aid the regenerating dendritic arbor and partially rescue defects in dendrite regeneration in adult animals.

\section{Dendrite ECM interaction has the potential to guide regeneration}

We observed preferential placement for regenerating dendrites on collagen IV, an ECM component. ECM cues may be derived from a combination of endogenous ECM patterning and changes in the extracellular environment observed after injury. Injury is a complex process that affects both the neuron and surrounding tissues, including the ECM. Studies of axon reinnervation of the neuromuscular junction after injury similarly suggest that existing extracellular cues guide regeneration. Regenerated synapses almost exclusively repopulate pre-existing synapse locations that are rich in basal lamina and the cues necessary for synapse maturation (Sanes and Chiu 1983). Moreover, therapeutic interventions have been proposed through the introduction of collagen scaffolds as a tool for the delivery of growth cues and structural preservation (Cholas et al. 2012). Proregenerative qualities have been ascribed to exogenous collagen XII in zebrafish spinal cord regeneration (Wehner et al. 2017). Our experiments suggest that the ECM plays an important role in dendrite outgrowth after injury. It will be of interest to characterize the precise cues that are instructive for dendrite regrowth in future studies.

Another interesting avenue for future studies concerns how neuronal regulation of ECM interaction influences dendrite regeneration. Integrin has been proposed as a target for increasing neurite regrowth (Platman 2012). Studies of axon regeneration have linked integrin activation to improved outgrowth in dorsal root ganglion neurons (Vogelezang et al. 2001; Ekström et al. 2003; Hu and Strittmatter 2008; Andrews et al. 2009; Tan et al. 2011, 2012). In retinal neurons, treatments to increase integrin expression enabled neurons to increase neurite outgrowth in laminin-poor environments, which are typically unfavorable to growth (Ivins et al. 2000). Older cultured neurons have also shown increased neurite growth upon increasing integrin expression (Condic 2001; Lemons and Condic 2008). We did not observe an increase in dendrite regeneration upon integrin overexpression in vivo, while decreasing integrin expression caused a decrease of dendrite regeneration. This suggests that integrin expression is important to regeneration but is insufficient to increase dendrite outgrowth after injury in mature animals.

This study provides a platform for future exploration of the molecular mediators of dendrite regeneration. Here, we establish that dendrite regeneration in adult Drosophila occurs throughout adulthood. The regenerated dendrites have impaired growth, microtubule stability, and self-avoidance when compared with dendrites of uninjured neurons. Moreover, our studies indicate that the capacity for regeneration decreases with age and the maturation of surrounding tissues and identify the ECM that is subject to remodeling and the ability of neurons to adhere to the ECM via integrins as factors important for dendrite regeneration.

\section{Materials and methods}

\section{Dendrite injury}

We designed a disc to image adult flies (Fig. 1A; Supplemental Fig. S1A). The disc was cut from 0.125 -in acrylic plastic by a ULS laser cutter. A circle of 2.25-in diameter with a rectangular groove and 
a hole offset in the center was cut. The center of the rectangular groove was filled with foam to cushion the adult flies. Magnetic strips with adhesive $1 \times 0.5 \times 0.06$ in (Magnet Source) were used to secure coverslips in place. The small hole was used to facilitate attachment to a carbon dioxide line. Flies were temporarily anesthetized on ice and then mounted in this chamber using water as a mounting medium. During imaging sessions, a light flow of carbon dioxide was used to anesthetize and immobilize the flies. Flies were injured using a custom-built Zeiss microscope using a Chameleon laser (Coherent) set at $930 \mathrm{~nm}$ as described previously (Song et al. 2012; Thompson-Peer et al. 2016). After injury, flies were housed individually in food vials with yeast. Subsequent imaging was performing on an SP5 confocal microscope. All experiments were performed using male flies.

\section{Fly stocks}

We used ;;ppkCD4tdGFP lines (Han et al. 2011) to visualize the c4da neurons in adult Drosophila. Mef2 Gal4 was used to mark muscles in the adult abdomens. Studies of $p p k 26$ were performed using ppk26 $6^{\Delta 11}$ and $D f(3 L) e^{2 x} l^{8104}$ (BL 7929). Studies of mmp2 were performed using $\mathrm{y}^{1} \mathrm{~W}^{*} ; \mathrm{Mi}\left\{\mathrm{MIC} / \mathrm{mmp} 2^{\mathrm{MIO0489}} / \mathrm{CyO}\right.$ (BL 31026), $w^{1118}$ Df(2R) BSC132/SM6a (BL 9410), mmp2 RNAi line (v107888), and mmp2 ${ }^{Y 53 N}$ (Page-McCaw et al. 2003; Wang and Page-McCaw 2014). UAS-dcr2 was used in combination with $m m p 2$ RNAi to knock down mmp2. Knockdown studies in the epithelial cells were done using GMR51F10 Gal4 (Losick et al. 2013). To visualize the BM, we used endogenously tagged collagen IV (vkgGFP). Overexpression studies were performed using ppkCD4tdGFP ${ }^{1 b}$; ppkGa14 ${ }^{1 a}$ crossed to w; UAS-mys, UAS-aPS1/ TM6B, Tb (Han et al. 2012). We used mew RNAi (BL44553) and mys RNAi (BL33642); knockdown of mew and mys was confirmed by expression in the wing disk and observation of a failure of the wing to fuse (Goulas et al. 2012).

\section{Quantitative analysis}

Dendrite length was calculated by tracing dendritic arbors using the Simple Neurite Tracer plug-in in ImageJ $1.51 \mathrm{n}$ (National Institutes of Health). Dendrite area was calculated by outlining the neuron and measuring dendrite coverage area. This measurement was normalized to the area of the segment, as defined by the width and height of the segment. For all graphs, open circles represent uninjured neurons, and solid squares represent injured neurons.

Colocalization was analyzed in Imaris (Bitplane). Leica files were deconvoluted with Autoquant (Media Cybernetics) and processed using parameters described previously (Han et al. 2012; Meltzer et al. 2016). Neurons were traced in the GFP channel and the colocalization channel. The ratio of colocalized dendrites to GFP dendrites was compared.

$\mathrm{XZ}$ projections were generated in ImageJ. Images were rotated to align muscles perpendicularly for and cropped to comparable areas.

\section{Immunohistochemistry}

Adult abdomens were dissected (Krupp and Levine 2010) and fixed for $30 \mathrm{~min}$ in $4 \%$ paraformaldehyde. Antibodies used were rabbit Ppk-26 (1:10,000) (Gorczyca et al. 2014) and mouse Futsch 22C (1:50; Developmental Studies Hybridoma Bank) (Hummel et al. 2000).

Using the measure tool of ImageJ, Futsch intensity was quantified by measuring Futsch intensity in primary branches over three lines (width $=3$ lines) proximal to the cell body and normalized to GFP in that branch. All images were acquired with the same settings. These areas were averaged for each neuron, and the averages were compared between neurons.

\section{Electrophysiological recordings}

Fillet preparations were made by dissecting male flies $8 \mathrm{~d}$ after eclosion in hemolymph-like saline containing $103 \mathrm{mM} \mathrm{NaCl}, 3$ $\mathrm{mM} \mathrm{KCl}, 5 \mathrm{mM}$ TES, $10 \mathrm{mM}$ trehalose, $10 \mathrm{mM}$ glucose, $7 \mathrm{mM}$ sucrose, $26 \mathrm{mM} \mathrm{NaHCO}_{3}, 1 \mathrm{mM} \mathrm{NaH}_{2} \mathrm{PO}_{4}, 4 \mathrm{mM} \mathrm{MgCl}_{2}$ (adjusted to $\mathrm{pH} 7.25)$, and $310 \mathrm{mM}$ mOsm. $\mathrm{Ca}^{2+}(2 \mathrm{mM})$ was added to the saline before use. c4da neurons in segments A2, A3, and A4 were exposed by gently removing muscles with fine forceps. $v^{\prime}$ ada neurons were visualized and identified by GFP driven by ppk promoter. Glass electrodes for electrophysiological recording were pulled with a P-97 puller (Sutter instruments) from thick-walled borosilicate glass and filled with external saline solution. Action potentials were recorded extracellularly with a sample rate of $10 \mathrm{kHz}$ and low-pass-filtered at $1 \mathrm{kHz}$. Multiclamp 700B amplifier, DIGIDITA 1440A, and Clampex 10.3 software (Molecular Devices) were used to acquire and process the data. A train of action potentials was induced by a 1-sec puff application of acidified external saline ( $\mathrm{pH} 3-7)$ at the distal dendritic area through a glass electrode attached to Picospritzer III (Parker Hannifin Precision Fluidics Division). Firing frequency within 2 sec before and after the puff was calculated, and the change in firing frequency was used to quantify the intensity of the response to low $\mathrm{pH}$ stimulation.

\section{Acknowledgments}

We thank Caitlin O'Brien, Jacob Jaszczak, Smita Yadav, Shan Meltzer, Maja Petkovic, and Mihir Vohra for critical reading of the manuscript, and Matt Klassen and Susan Younger for technical help. Andrea Page-McCaw provided stocks for this study. This work was supported by K99NS097627 to K.L.T.-P., and National Institutes of Health grant numbers R37NS040929 and R35NS097227 to Y.N.J. L.Y.J. and Y.N.J. are investigators of the Howard Hughes Medical Institute.

Author contributions: L.D. and Y.N.J. conceived and designed the study. L.D. performed the experiments with T.L. for the electrophysiology and with S.I. for the immunohistochemistry. L.D. analyzed the data. L.D, K.L.T.-P., L.Y.J., and Y.N.J. wrote the paper. All authors discussed the results and commented on the manuscript.

\section{References}

Andrews MR, Czvitkovich S, Dassie E, Vogelaar CF, Faissner A, Blits B, Gage FH, ffrench-Constant C, Fawcett JW. 2009. a9 integrin promotes neurite outgrowth on tenascin-C and enhances sensory axon regeneration. J Neurosci 29: 5546-5557.

Andries L, Van Hove I, Moons L, De Groef L. 2017. Matrix metalloproteinases during axonal regeneration, a multifactorial role from start to finish. Mol Neurobiol 54: 2114-2125.

Boiko N, Kucher V, Stockand JD, Eaton BA. 2012. Pickpocket1 is an ionotropic molecular sensory transducer. J Biol Chem 287: 39878-39886.

Brace EJ, DiAntonio A. 2017. Models of axon regeneration in Drosophila. Exp Neurol 287: 310-317.

Cholas RH, Hsu HP, Spector M. 2012. The reparative response to cross-linked collagen-based scaffolds in a rat spinal cord gap model. Biomaterials 33: 2050-2059.

Condic ML. 2001. Adult neuronal regeneration induced by transgenic integrin expression. J Neurosci 21: 4782-4788. 
Dong X, Shen K, Bülow HE. 2015. Intrinsic and extrinsic mechanisms of dendritic morphogenesis. Annu Rev Physiol 77: 271-300.

Ekström PAR, Mayer U, Panjwani A, Pountney D, Pizzey J, Tonge DA. 2003. Involvement of $\alpha 7 \beta 1$ integrin in the conditioninglesion effect on sensory axon regeneration. Mol Cell Neurosci 22: 383-395.

Falke E, Nissanov J, Mitchell TW, Bennett DA, Trojanowski JQ, Arnold SE. 2003. Subicular dendritic arborization in Alzheimer's disease correlates with neurofibrillary tangle density. Am J Pathol 163: 1615-1621.

Ferreira T, Ou Y, Li S, Giniger E, van Meyel DJ. 2014. Dendrite architecture organized by transcriptional control of the F-actin nucleator Spire. Development 141: 650-660.

Gorczyca DA, Younger S, Meltzer S, Kim SE, Cheng L, Song W, Lee HY, Jan LY, Jan YN. 2014. Identification of Ppk26, a $\mathrm{DEG} / \mathrm{ENaC}$ channel functioning with Ppk1 in a mutually dependent manner to guide locomotion behavior in Drosophila. Cell Rep 9: 1446-1458.

Goulas S, Conder R, Knoblich JA. 2012. The Par complex and integrins direct asymmetric cell division in adult intestinal stem cells. Cell Stem Cell 11: 529-540.

Grueber WB, Jan LY, Jan YN. 2002. Tiling of the Drosophila epidermis by multidendritic sensory neurons. Development 129: 2867-2878.

Guo Y, Wang Y, Wang Q, Wang Z. 2014. The role of Ppk26 in Drosophila larval mechanical nociception. Cell Rep 9: 1183-1190.

Han C, Jan LY, Jan YN. 2011. Enhancer-driven membrane markers for analysis of nonautonomous mechanisms reveal neuron-glia interactions in Drosophila. Proc Natl Acad Sci 108: 9673-9678.

Han C, Wang D, Soba P, Zhu S, Lin X, Jan LY, Jan YN. 2012. Integrins regulate repulsion-mediated dendritic patterning of Drosophila sensory neurons by restricting dendrites in a $2 \mathrm{D}$ space. Neuron 73: 64-78.

Hu F, Strittmatter SM. 2008. The N-terminal domain of Nogo-A inhibits cell adhesion and axonal outgrowth by an integrinspecific mechanism. J Neurosci 28: 1262-1269.

Huang H, Du G, Chen H, Liang X, Li C, Zhu N, Xue L, Ma J, Jiao R. 2011. Drosophila Smt3 negatively regulates JNK signaling through sequestering Hipk in the nucleus. Development 138: $2477-2485$.

Hummel T, Krukkert K, Roos J, Davis G, Klämbt C. 2000. Drosophila Futsch/22C10 is a MAP1B-like protein required for dendritic and axonal development. Neuron 26: 357-370.

Hwang RY, Zhong L, Xu Y, Johnson T, Zhang F, Deisseroth K, Tracey WD. 2007. Nociceptive neurons protect Drosophila larvae from parasitoid wasps. Curr Biol 17: 2105-2116.

Ivins JK, Yurchenco PD, Lander AD. 2000. Regulation of neurite outgrowth by integrin activation. J Neurosci 20: 6551-6560.

Jan YN, Jan LY. 2010. Branching out: mechanisms of dendritic arborization. Nat Rev Neurosci 11: 316-328.

Jia Q, Liu Y, Liu H, Li S. 2014. Mmp1 and Mmp2 cooperatively induce Drosophila fat body cell dissociation with distinct roles. Sci Rep 4: 7535.

Jiang N, Soba P, Parker E, Kim CC, Parrish JZ. 2014. The microRNA bantam regulates a developmental transition in epithelial cells that restricts sensory dendrite growth. Development 141: 2657-2668.

Kim ME, Shrestha BR, Blazeski R, Mason CA, Grueber WB. 2012. Integrins establish dendrite-substrate relationships that promote dendritic self-avoidance and patterning in Drosophila sensory neurons. Neuron 73: 79-91.

Koleske AJ. 2013. Molecular mechanisms of dendrite stability. Nat Rev Neurosci 14: 536-550.
Kravtsov V, Oren-Suissa M, Podbilewicz B. 2017. The fusogen AFF-1 can rejuvenate the regenerative potential of adult dendritic trees via self-fusion. Development 144: 2364-2374.

Krupp JJ, Levine JD. 2010. Dissection of oenocytes from adult Drosophila melanogaster. J Vis Exp 18: 2242.

Kuo CT, Jan LY, Jan YN. 2005. Dendrite-specific remodeling of Drosophila sensory neurons requires matrix metalloproteases, ubiquitin-proteasome, and ecdysone signaling. Proc Natl Acad Sci 102: 15230-15235.

Kuo CT, Zhu S, Younger S, Jan LY, Jan YN. 2006. Identification of E2/E3 ubiquitinating enzymes and caspase activity regulating Drosophila sensory neuron dendrite pruning. Neuron 51: 283-290.

Lemons ML, Condic ML. 2008. Integrin signaling is integral to regeneration. Exp Neurol 209: 343-352.

Llano E, Adam G, Pendas AM, Quesada V, Sanchez LM, Santamaria I, Noselli S, Lopez-Otin C. 2002. Structural and enzymatic characterization of Drosophila Dm-MMP, a membrane-bound matrix metalloproteinase with tissue-specific expression. J Biol Chem 277: 23321-23329.

Losick VP, Fox DT, Spradling AC. 2013. Polyploidization and cell fusion contribute to wound healing in the adult Drosophila epithelium. Curr Biol 23: 2224-2232.

Mauthner SE, Hwang RY, Lewis AH, Xiao Q, Tsubouchi A, Wang Y, Hongjo K, Skene JH, Grandl J, Tracey WD. 2014. Balboa binds to pickpocket in vivo and is required for mechanical nociception in Drosophila larvae. Curr Biol 24: 2920-2925.

Meltzer S, Yadav S, Lee J, Soba P, Younger SH, Jin P, Zhang W, Parrish J, Jan LY, Jan YN. 2016. Epidermis-derived semaphorin promotes dendrite self-avoidance by regulating dendrite-substrate adhesion in Drosophila sensory neurons. Neuron 89: 741-755.

Miller CM, Page-McCaw A, Broihier HT. 2007. Matrix metalloproteinases promote motor axon fasciculation in the Drosophila embryo. Development 135: 95-109.

Oren-Suissa M, Gattegno T, Kravtsov V, Podbilewicz B. 2017. Extrinsic repair of injured dendrites as a paradigm for regeneration by fusion in Caenorhabditis elegans. Genetics 206: 215-230.

Page-McCaw A, Serano J, Santé JM, Rubin GM. 2003. Drosophila matrix metalloproteinases are required for tissue remodeling, but not embryonic development. Dev Cell 1: 95-106.

Page-McCaw A, Ewald AJ, Werb Z. 2007. Matrix metalloproteinases and the regulation of tissue remodelling. Nat Rev Mol Cell Biol 8: 221-233.

Parrish JZ, Xu P, Kim CC, Jan LY, Jan YN. 2009. The microRNA bantam functions in epithelial cells to regulate scaling growth of dendrite arbors in Drosophila sensory neurons. Neuron 63: 788-802.

Platman S. 2012. Integrin manipulation to improve regeneration. Cell Adh Migr 6: 451-453.

Sanes JR, Chiu AY. 1983. The basal lamina of the neuromuscular junction. Cold Spring Harb Symp Quant Biol 48: 667-678.

Satoh D, Suyama R, Kimura K, Uemura T. 2012. High-resolution in vivo imaging of regenerating dendrites of Drosophila sensory neurons during metamorphosis: local filopodial degeneration and heterotypic dendrite-dendrite contacts. Genes Cells 17: 939-951.

Sears JC, Broihier HT. 2016. FoxO regulates microtubule dynamics and polarity to promote dendrite branching in Drosophila sensory neurons. Dev Biol 418: 40-54.

Shimono K, Fujimoto A, Tsuyama T, Yamamoto-Kochi M, Sato M, Hattori Y, Sugimura K, Usui T, Uemura T. 2009. Multidendritic sensory neurons in the adult Drosophila abdomen: 
DeVault et al.

origins, dendritic morphology, and segment- and age-dependent programmed cell death. Neural Dev 4: 37.

Shimono K, Fujishima K, Nomura T, Ohashi M, Usui T, Kengaku M, Toyoda A, Uemura T. 2014. An evolutionarily conserved protein CHORD regulates scaling of dendritic arbors with body size. Sci Rep 4: 4415.

Soares L, Parisi M, Bonini NM. 2014. Axon injury and regeneration in the adult Drosophila. Sci Rep 4: 6199.

Song Y, Ori-McKenney KM, Zheng Y, Han C, Jan LY, Jan YN. 2012. Regeneration of Drosophila sensory neuron axons and dendrites is regulated by the Akt pathway involving Pten and microRNA bantam. Genes Dev 26: 1612-1625.

Stevens LJ, Page-McCaw A. 2012. A secreted MMP is required for reepithelialization during wound healing. Mol Biol Cell 23: 1068-1079.

Stone MC, Albertson RM, Chen L, Rolls MM. 2014. Dendrite injury triggers DLK-independent regeneration. Cell Rep 6: 247-253.

Tan CL, Kwok JC, Patani R, ffrench-Constant C, Chandran S, Fawcett JW. 2011. Integrin activation promotes axon growth on inhibitory chondroitin sulfate proteoglycans by enhancing integrin signaling. J Neurosci 31: 6289-6295.

Tan CL, Andrews MR, Kwok JC, Heintz TG, Gumy LF, Fassler R, Fawcett JW. 2012. Kindlin-1 enhances axon growth on inhibitory chondriotin sulfate proteoglycans and promotes sensory axon regeneration. J Neurosci 32: 7325-7335.

Thompson-Peer KL, DeVault L, Li T, Jan LY, Jan YN. 2016. In vivo dendrite regeneration after injury is different from dendrite development. Genes Dev 30: 1776-1789.
Tracey WD, Wilson RI, Laurent G, Benzer S. 2003. Painless, a Drosophila gene essential for nociception. Cell 113: 261-273.

Vickers JC, Mitew S, Woodhouse A, Fernandez-Martos CM, Kirkcaldie MT, Canty AJ, McCormack GH, King AE. 2016. Defining the earliest pathological changes of Alzheimer's disease. Curr Alzheimer Res 13: 281-287.

Vogelezang MG, Liu Z, Relvas JB, Raivich G, Scherer SS, ffrenchConstant C. 2001. a4 integrin is expressed during peripheral nerve regeneration and enhances neurite outgrowth. I Neurosci 21: 6732-6744.

Wang X, Page-McCaw A. 2014. A matrix metalloproteinase mediates long-distance attenuation of stem cell proliferation. J Cell Biol 7: 923-936.

Wehner D, Tsarouchas TM, Michael A, Haase C, Weidinger G, Reimer MM, Becker T, Becker CG. 2017. Wnt signaling controls pro-regenerative collagen XII in functional spinal cord regeneration in zebrafish. Nat Commun 8: 126.

Williams DW, Truman JW. 2005a. Cellular mechanisms of dendrite pruning in Drosophila: insights from in vivo time-lapse of remodeling dendritic arborizing sensory neurons. Development 132: 3631-3642.

Williams DW, Truman JW. 2005b. Remodeling dendrites during insect metamorphosis. J Neurobiol 64: 24-33.

Xiang Y, Yuan Q, Vogt N, Looger LL, Jan LY, Jan YN. 2010. Lightavoidance-mediating photoreceptors tile the Drosophila larval body wall. Nature 468: 921-926.

Yasunaga K, Kanamori T, Morikawa R, Suzuki E, Emoto K. 2010. Dendrite reshaping of adult Drosophila sensory neurons requires matrix metalloproteinase-mediated modification of the basement membranes. Dev Cell 18: 621-632. 


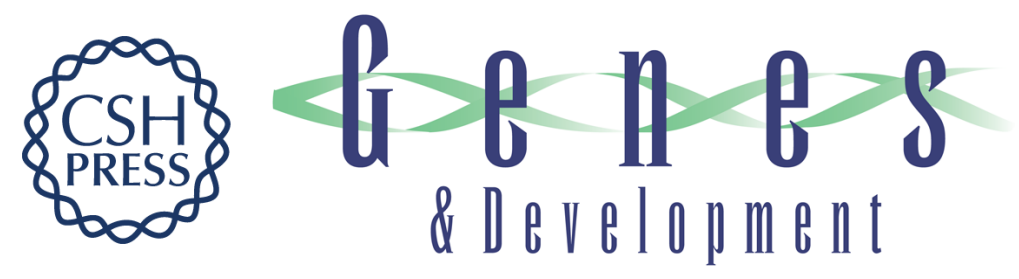

\section{Dendrite regeneration of adult Drosophila sensory neurons diminishes with aging and is inhibited by epidermal-derived matrix metalloproteinase 2}

Laura DeVault, Tun Li, Sarah Izabel, et al.

Genes Dev. 2018, 32: originally published online March 21, 2018

Access the most recent version at doi:10.1101/gad.308270.117

Supplemental Material

References

Creative

Commons

License

Email Alerting

Service
http://genesdev.cshlp.org/content/suppl/2018/03/21/gad.308270.117.DC1

This article cites 62 articles, 21 of which can be accessed free at: http://genesdev.cshlp.org/content/32/5-6/402.full.html\#ref-list-1

This article is distributed exclusively by Cold Spring Harbor Laboratory Press for the first six months after the full-issue publication date (see http://genesdev.cshlp.org/site/misc/terms.xhtml). After six months, it is available under a Creative Commons License (Attribution-NonCommercial 4.0 International), as described at http://creativecommons.org/licenses/by-nc/4.0/.

Receive free email alerts when new articles cite this article - sign up in the box at the top right corner of the article or click here.

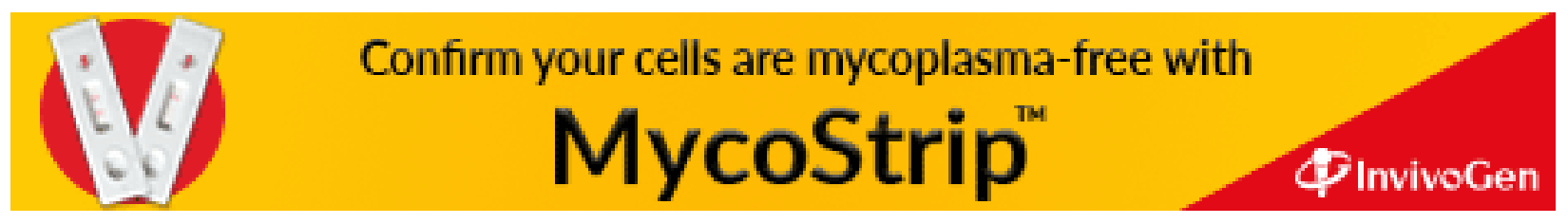

